\title{
Using the Job-Demands-Resources (JD-R) Model in Predicting the Resilience of the Melli Bank Branch Employees of Kerman, Iran
}

\author{
${\text { Fereshteh Mohseni Takalu1(D), Sanjar Salajeghe }{ }^{2 *(D)} \text {, Mohammad Jalalkamali }}^{3}$ (D), \\ Mohammad Taghi Mohseni Takalu ${ }^{4}$ (D)
}

1. PhD Student, Department of Management, Faculty of Literature and Humanities, Kerman Branch, Islamic Azad University, Kerman, Iran

2. Associate Professor, Department of management, Faculty of Literature and Humanities, Kerman Branch, Islamic Azad University, Kerman, Iran

3. Assistant Professor, Department of Management, Faculty of Literature and Humanities, Kerman Branch, Islamic Azad University, Kerman, Iran

4. Assistant Professor, Department of Rehabilitation, Faculty of Allied Medicine, Kerman University of Medical Sciences, Kerman, Iran

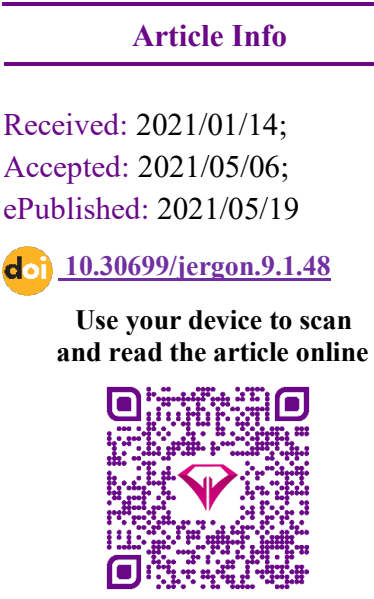

Corresponding Author Sanjar Salajeghe Associate Professor, Department of management, Faculty of Literature and Humanities, Kerman Branch, Islamic Azad University, Kerman, Iran

Email:

s.salajeghe@,iauk.ac.ir

\begin{abstract}
Background and Objectives: Resilience is one of the factors affecting the job performance of employees and maintaining their health in a stressful work environment. This study aimed to apply the Job Demands-Resources (JD-R) model to investigate the individual resilience and the factors affecting it in Melli Bank branch employees of Kerman, Iran.
\end{abstract}

Methods: In this self-reported cross-sectional survey, 358 Melli Bank Branch Employees of Kerman city participated from August to December 2019. According to the JD-R model, the constructs including resilience, emotional intelligence, social support, and job stress, were selected as outcome, personal resource, job resource, and Job demand respectively and participants participated in the survey by answering the questionnaire designed based on these four constructs. Data were analyzed using SPSS 23 and AMOS 21 software.

Results: The results showed that resources (emotional intelligence and social support) and demand (job stress) are directly and separately related to resilience $(P<0.001$ and $P=0.006$, respectively), and they are also interactively related (interaction of emotional intelligence and job stress, social support and job stress, social support and emotional intelligence) $(P<0.001, P<0.001$, and $P=0.003$ respectively).

Conclusion: Emotional intelligence, social support, and job stress can affect the resilience of bank employees and human resource managers in banks can help increase employee resilience by creating educational interventions in these areas.

Keywords: Demands-Resources Model, Resilience, Job stress, Emotional intelligence, Social support

Copyright (C) 2021, This is an original open-access article distributed under the terms of the Creative Commons Attribution-noncommercial 4.0 International License which permits copy and redistribute of the material just in noncommercial usages with proper citation.

How to Cite This Article:

Mohseni Takalu F, Salajeghe S, Jalalkamali M, Mohseni Takalu M T. Using the Job-Demands-Resources (JD-R) model in predicting the resilience of the Melli Bank Branch Employees of Kerman city. Iran J Ergon. 2021; 9 (1) :48-62. 


\section{Extended Abstract}

\section{Introduction}

Resilience is one of the factors affecting the job performance of employees and maintaining their health in a stressful work environment. This study aimed to apply the Job Demands-Resources (JDR) model to investigate the individual resilience and the factors affecting it in Melli Bank branch employees of Kerman, Iran.

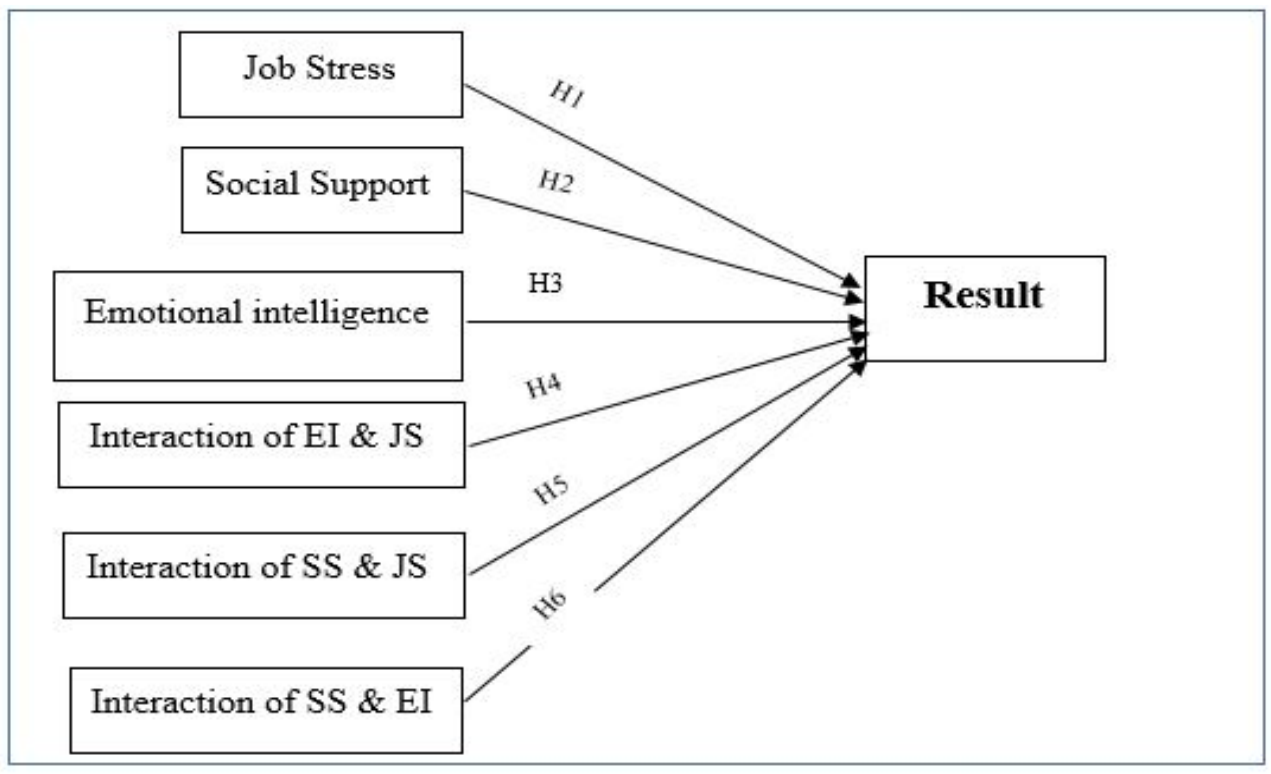

Figure 1. Conceptual model derived from study hypotheses. H: Hypothesis; Res: resilience; JS: Job stress; SS: Social Support; EI: Emotional intelligence

\section{Methods}

In this self-reported cross-sectional survey, 358 Melli Bank Branch Employees of Kerman city participated from August to December 2019. According to the JD-R model, the constructs including resilience, emotional intelligence, social support, and job stress, were selected as outcome, personal resource, job resource, and Job demand respectively and participants participated in the survey by answering the questionnaire designed based on these four constructs. Data were analyzed using SPSS 23 and AMOS 21 software.

\section{Results}

The results showed that resources (emotional intelligence and social support) and demand (job stress) are directly and separately related to resilience ( $P<0.001$ and $P=0.006$, respectively), and they are also interactively related (interaction of emotional intelligence and job stress, social support and job stress, social support and emoti-onal intelligence) $(P<0.001, P<0.001$, and $P=0.003$ respectively). 


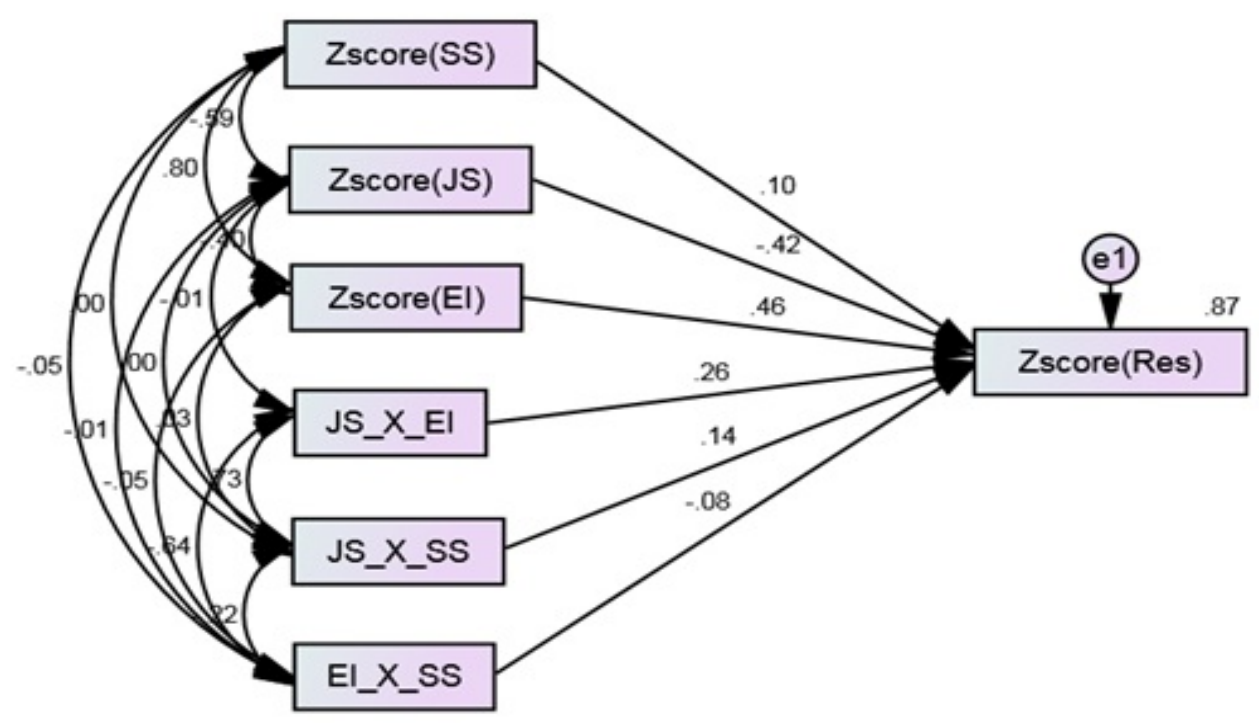

Figure 2. Results of the structural model derived from the conceptual model. Zscore: standardized score; _ X_: interaction between two structures; Res: resilience; SS: Social Support; JS: Job stress; EI: Emotional intelligence

A
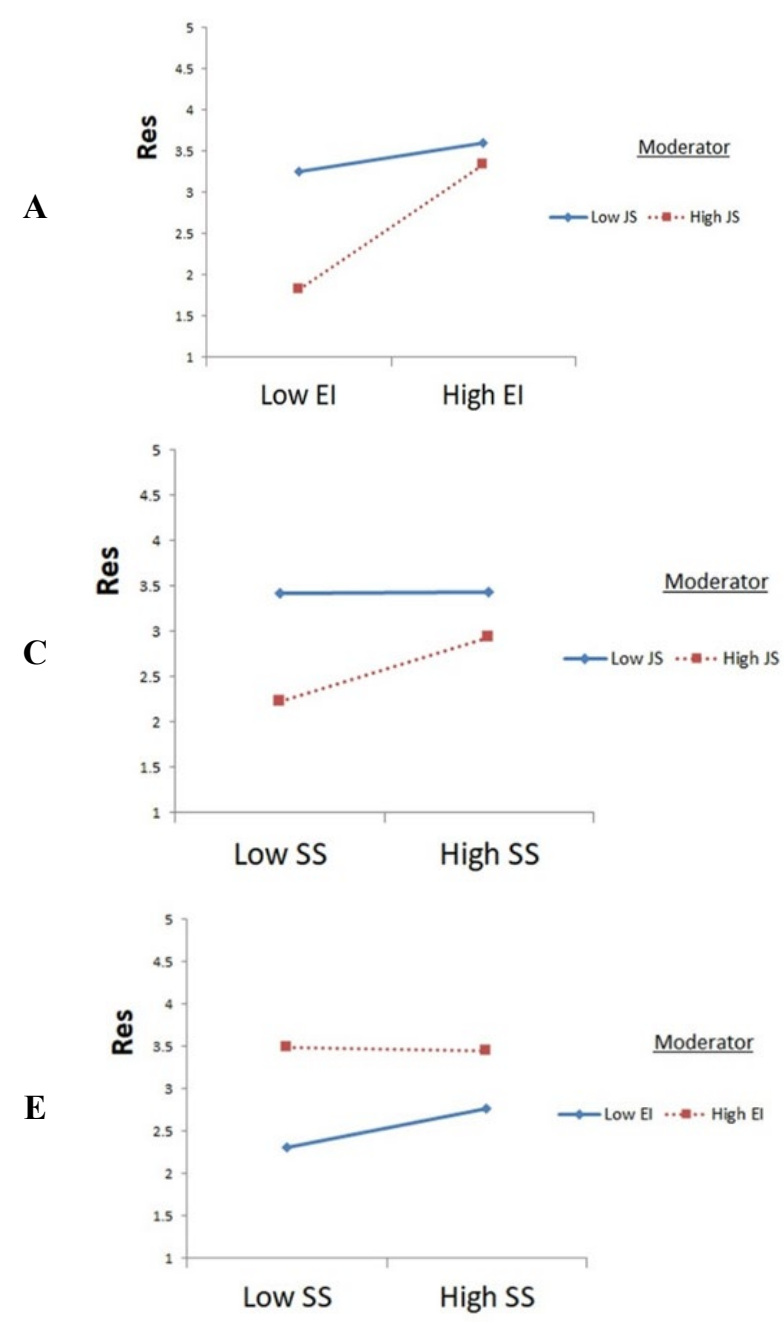

B

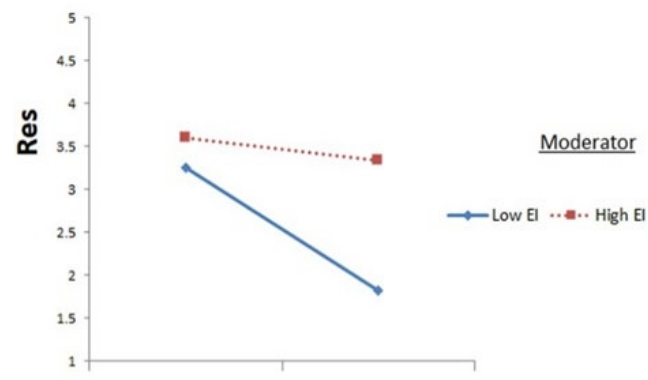

Low JS High JS
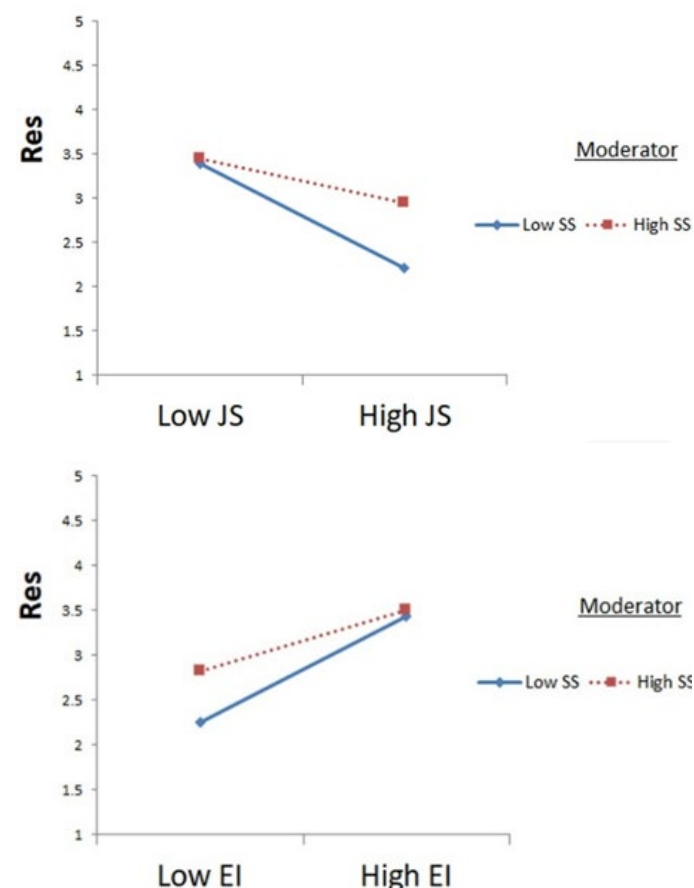

Figure 3. Simple slope diagram of the fourth to sixth study hypotheses. Moderator: Modifier; High: high (more); Low: Res: resilience; SS: Social Support; JS: Job stress; EI: Emotional intelligence 


\section{Discussion}

The aim of this study was to investigate the relationship between job stress, social support, emotional intelligence and also two way interactions of these three variables with resilience in the form of JD-R model. The relationship between job stress and resilience (first hypothesis) in this study was negative and significant $(P<0.001$ and $\beta=-0.42)$. Hansen in his study examining the relationship between job stress and managers 'resilience and health, concluded that job stress has a negative relationship with managers' resilience and can endanger their health [26]. According to the second hypothesis, perceived social support had a positive and significant relationship with resilience $(P=$ 0.006 and $\beta=0.10)$. A recent study in this regard showed that social support from the family has a significant and positive effect on the resilience of bank employees [27]. According to the third hypothesis, emotional intelligence had a positive and significant relationship with resilience $(P<0.001$ and $\beta=0.46$ ). Some other studies have suggested that more emotional intelligence leads to better resilience [16]. In the present study, the fourth hypothesis that the interaction effect of job stress and emotional intelligence with resilience was significant was also confirmed $(P<0.001$ and $\beta=$ 0.26). Figure 2 ( $\underline{A}$ and $\underline{B}$ ) shows a simple slope analysis of the fourth hypothesis that job stress and emotional intelligence have played a moderating role in this interaction, respectively. Figure A2 also shows that job stress has a more negative effect on the resilience of people with lower emotional intelligence. It also shows that increased job stress has increased the relationship between emotional intelligence and resilience. In this regard, other studies show that when an employee is faced with a challenging (not threatening) job stress, the role of resources becomes more valuable and has a greater impact on the outcome [28]. Figure B2 also shows a situation in which emotional intelligence plays a moderating role in this interaction. This figure shows that the higher the job stress, the greater the buffering effect on emotional intelligence and the weaker the negative relationship between job stress and resilience. Kinman and Grant also found in their study that social workers with high emotional adequacy were more resilient and had less burnout [29]. In the present study, the fifth hypothesis regarding the significance of the interactive effect of job stress and social support on resilience was confirmed $(P<0.001$ and $\beta=0.14)$. Studying Figure $\mathrm{C} 2$, which shows the moderating role of job stress in this interaction, it can be observed that low levels of job stress did not have much effect on the relationship between social support and resilience, but when the level of job stress increased, it played a buffering role and positively strengthened the relationship between social support and resilience. In this regard, Cooke, Bartram and Wang, with the aim of investigating the impact of social support on individual resilience of 2025 bank employees, concluded that these two have a positive and significant relationship with each other and high workload moderates and strengthens this positive relationship] [14]. Figure D2 also shows the situation of the fifth hypothesis that social support has played a moderating role between job stress and resilience. This Figure shows that in low-stress situations, social support did not play a significant role in increasing resilience, but in stressful situations, it played a buffering role and weakened the negative relationship between job stress and resilience. In this regard, a study of caregivers of people with Alzheimer's disease showed that care-related stress has a negative effect on their resilience and social support has moderated and weakened this negative relationship [30]. In the present study, the sixth hypothesis considering the significant interacttive effect of emotional intelligence and social support with resilience was confirmed $(P=0.003$ and $\beta$ $=-0.08)$. Figures E2 and F2 are related to the sixth hypothesis. In Figure E2, emotional intelligence plays a moderating role. In employees with higher emotional intelligence, the level of social support had little effect on their resilience. Also in Figure $\underline{F 2}$, by playing the role of social support as a moderator, it is clear that social support has a buffering role only for people with low emotional intelligence and has strengthened the positive relationship between emotional intelligence and resilience, but in people with high emotional intelligence, this buffering role of social support, is 
weak and negligible; thus, the personal source of emotional intelligence may have been more important in maintaining and promoting the resilience of participating employees than the occupational source of social support. Human resource managers can use the results of this study to help select and hire new resilient staff. They can also use training programs related to emotional intelligence and improve social relationships to gain the desired social support to increase the resilience of employyees in the stressful environment of the bank.

\section{Conclusion}

Emotional intelligence, social support, and job stress can affect the resilience of bank employees and human resource managers in banks can help increase employee resilience by creating educational interventions in these areas.

\section{Acknowledgement}

The authors would like to thank all those who helped them in this research. This research is approved by the ethics committee of Islamic Azad University, Kerman branch with the code IR.IAU.KERMAN.REC.1399.008.

\section{Conflict of Interest}

The authors declared no conflict of interest. 


\section{مقالهُ يزوهشى}

استفاده از مدل الزامات-منابع شغلى در ييشبينى تابآورى كاركنان شعب بانك ملى شهر كرمان

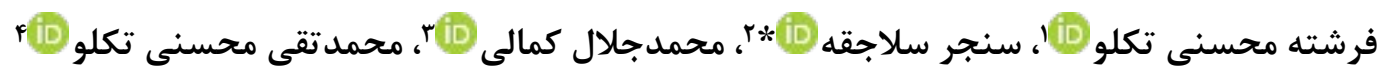

'. . دانشجوى دكتراى تخصصى مديريت دولتى، كروه مديريت، دانشكدة ادبيات و علوم انسانى، واحد كرمان، دانشكاه آزاد اسلامى، كرمان، ايران

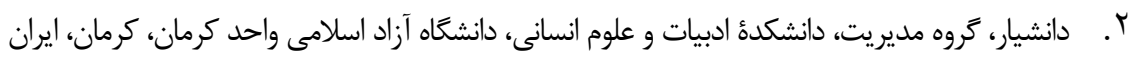

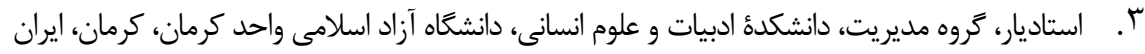

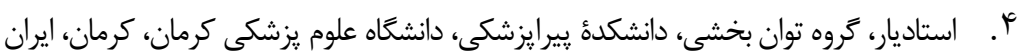

\begin{tabular}{|c|c|}
\hline خلاصه & اطلاعات مقاله \\
\hline 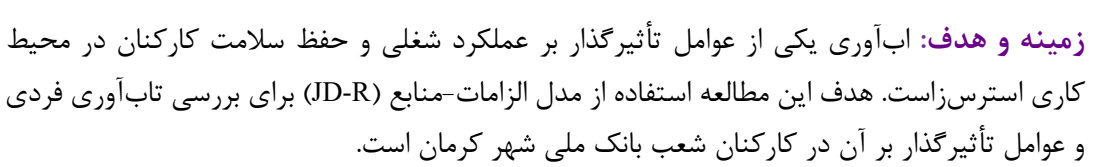 & 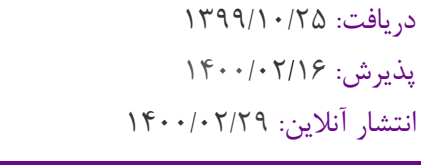 \\
\hline 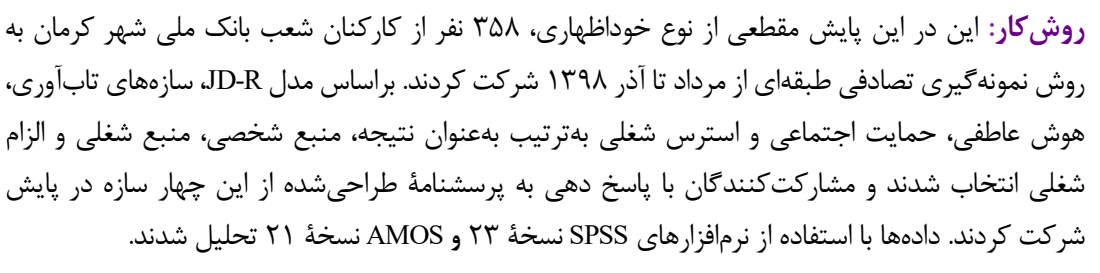 & 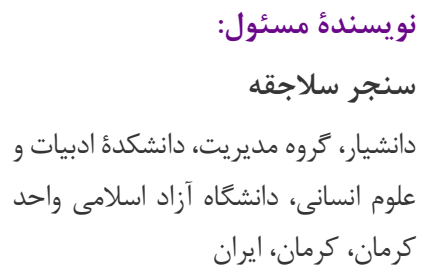 \\
\hline 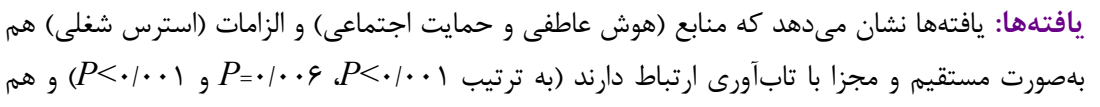 & $\begin{array}{l}\text { يست الكترونيك: } \\
\text { S.salajeghe@iauk.ac.ir }\end{array}$ \\
\hline 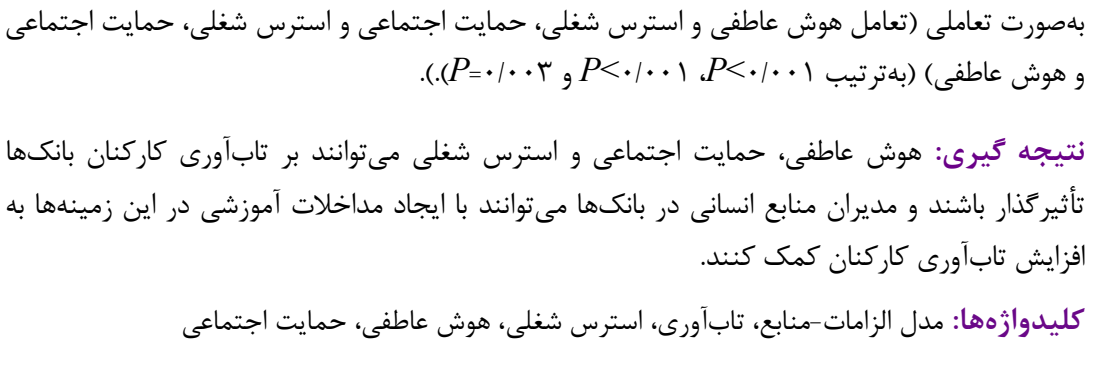 & 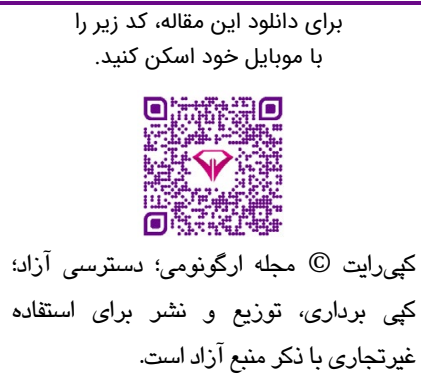 \\
\hline
\end{tabular}

مقدمه

تاب آورى مهمترين عامل براى كنارآمدن با مشكلات محل كار

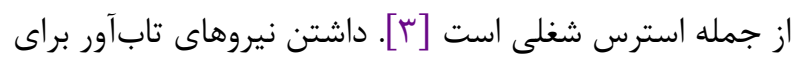

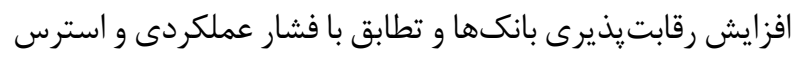

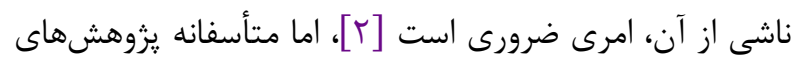

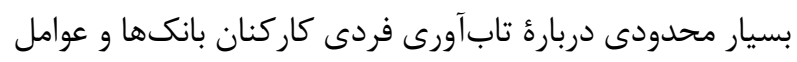

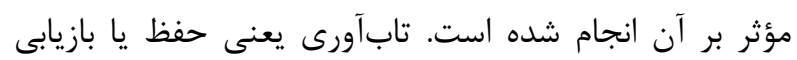

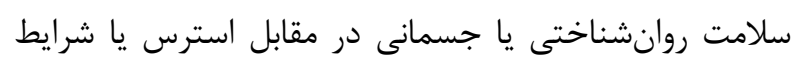

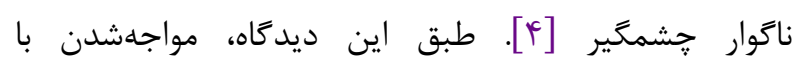

تغييرات در سازمان و ساختار بانكها و ورود فناورىهاى

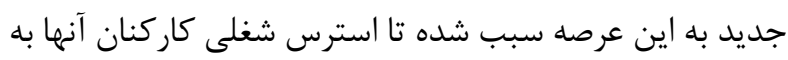

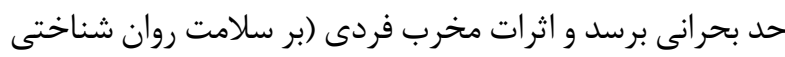

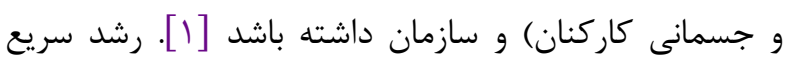

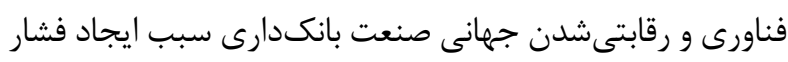

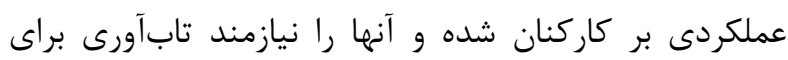

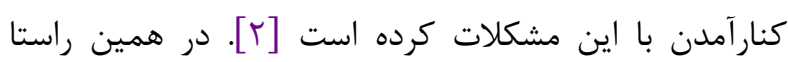

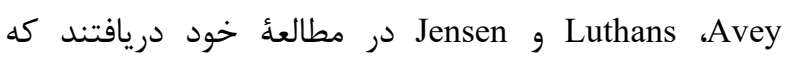


شبكؤ اجتماعى را خانواده، دوستان و ساير افراد مههم (همجون

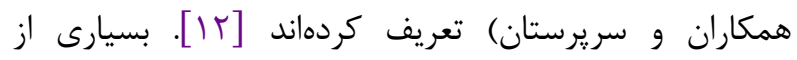

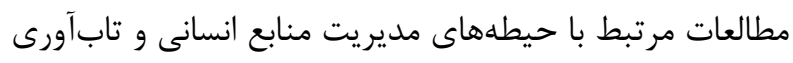

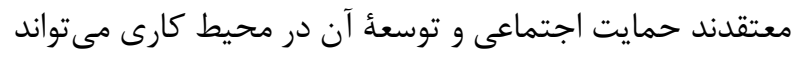

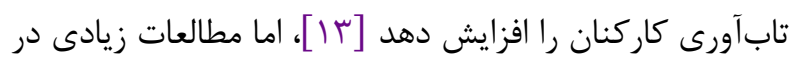

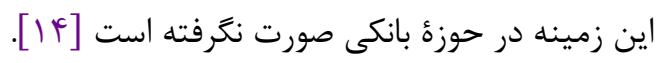

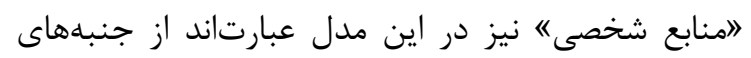

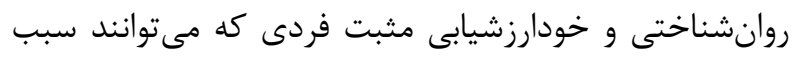

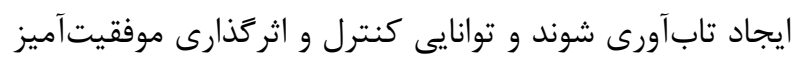

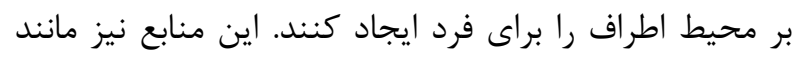

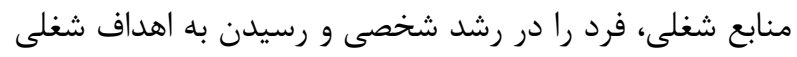

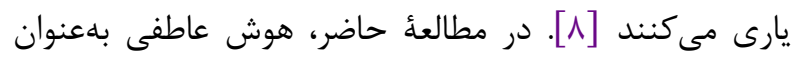

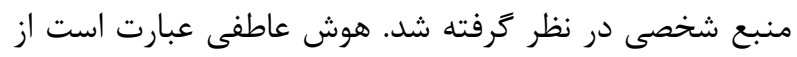

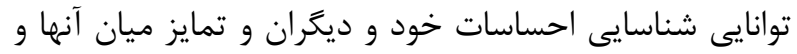

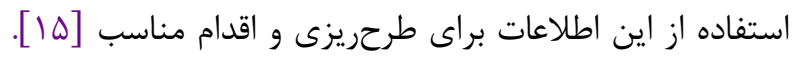

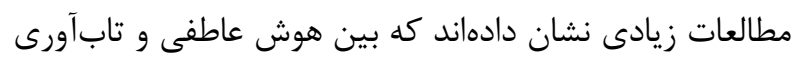

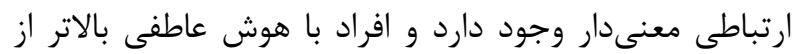

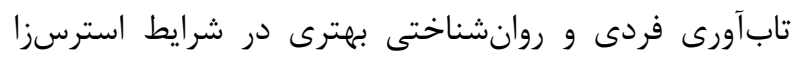

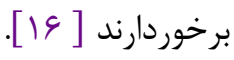
مدل JD-R معتقد است منابع و الزامات شغلى علاوه بر اثرات مجزاى خود، اثرات مشترك و تعاملى (interaction effect) نيز

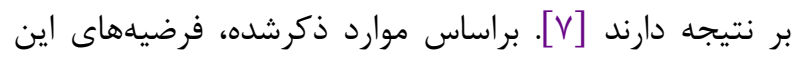
مطالعه در ادامه بيان شده است: فرضيئ اول: استرس شغلى (الزام شغلى) با تابآورى (نتيجه)

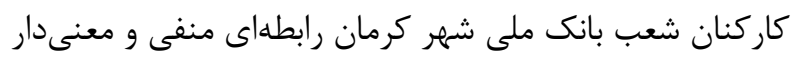

فرضيئ دوم: حمايت اجتماعى (منبع شغلى) با تابآورى (نتيجه) كار كنان شعب بانك ملى شهر كرمان رابطهاى مثبت و و

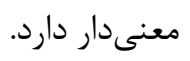

فرضيئ سوم: هوش عاطفى (منبع شخصى) با تابآورى (نتيجه) كاركنان شعب بانك ملى شهر كرمان رابطهاى مثبت و واطعا

$$
\text { معنى دار دارد. - ماركان }
$$

فرضئ جههارم: تعامل استرس شغلى (الزام شغلى) و هوش (مارد عاطفى (منبع شخصى)، رابطهاى معنىدار با تابآورى (نتيجه) كاركنان شعب بانك ملى شهر كرمان خواهند داشت.
موقعيتهاى استرسزا، پِيشنياز و الزام تابآورى است و

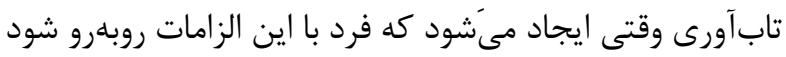

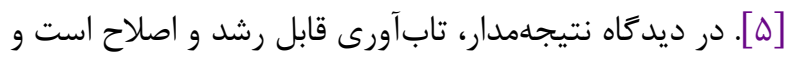
توسط عوامل متعدد درونى (شخصى) و بيرونى (محيطى

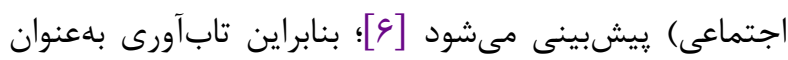

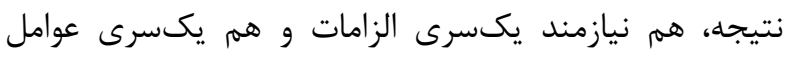
شخصى و محيطى است. اين مفاهيم مىتوانند همارز مفاهيم نداريم

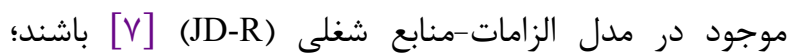

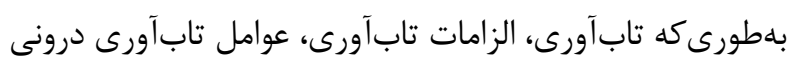

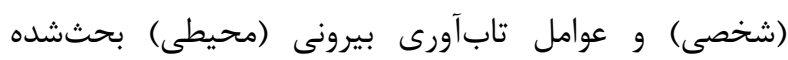

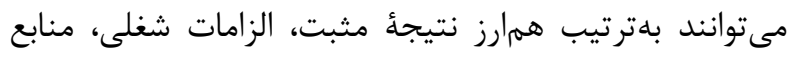

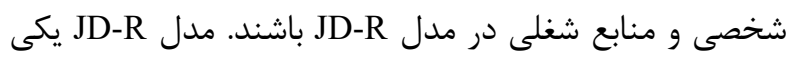

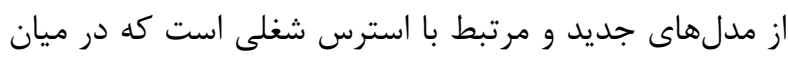
محققان از محبوبت و مقبوليت بالايى برخوردار است [^] و و

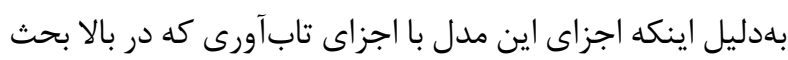

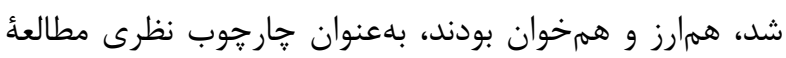

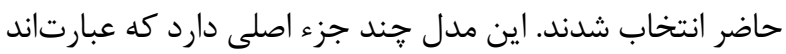

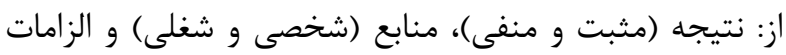

شغلى [1].

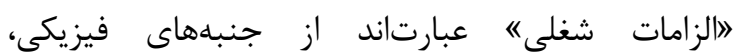

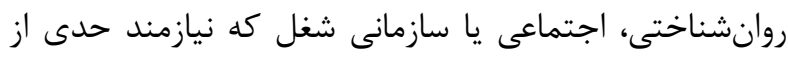

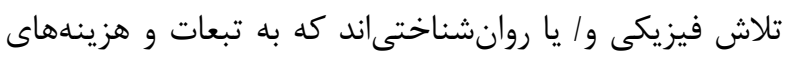

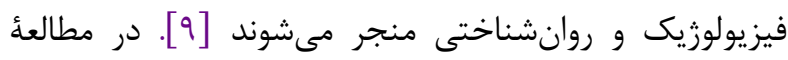
حاضر بهدليل وجود استرس شغلى بحرانى در صنعت بانكدارى

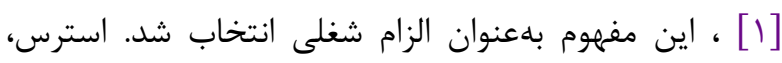

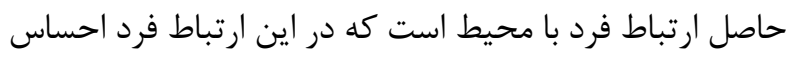

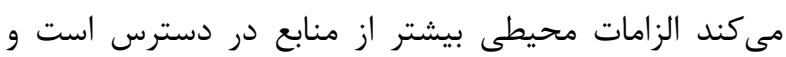

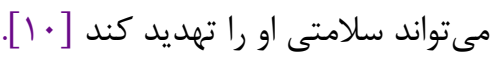

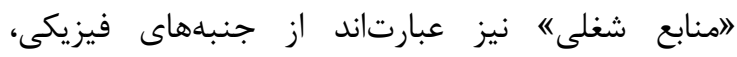
روانشناختى، اجتماعى يا سازمانى شغل كه ممكن است عارئ عاملى إنى

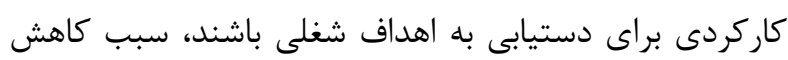

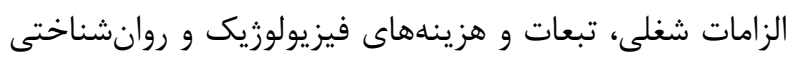

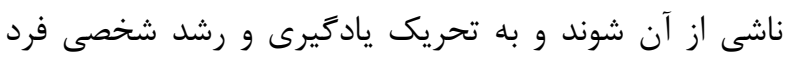

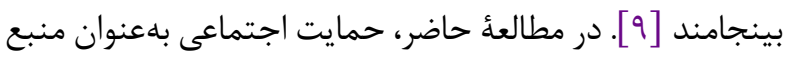

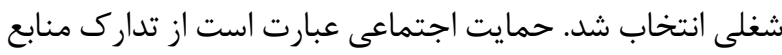

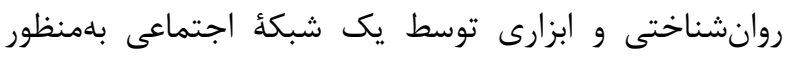

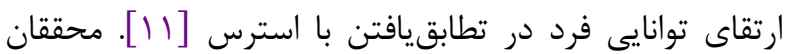


فرضئُ ششم: تعامل هوش عاطفى (منبع شخصى) و حمايت

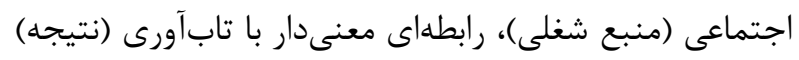

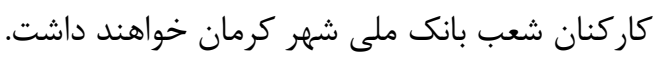
شكل ا مدل مفهومى مطالعه حاضر را نشان مى دهان خوند.
فرضئُ ينجم: تعامل استرس شغلى (الزام شغلى) و حمايت

اجتماعى (منبع شغلى)، رابطهاى معنى دار با تاب آورى (نتيجه)

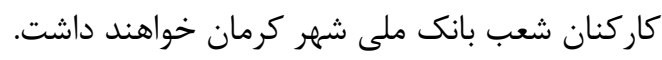

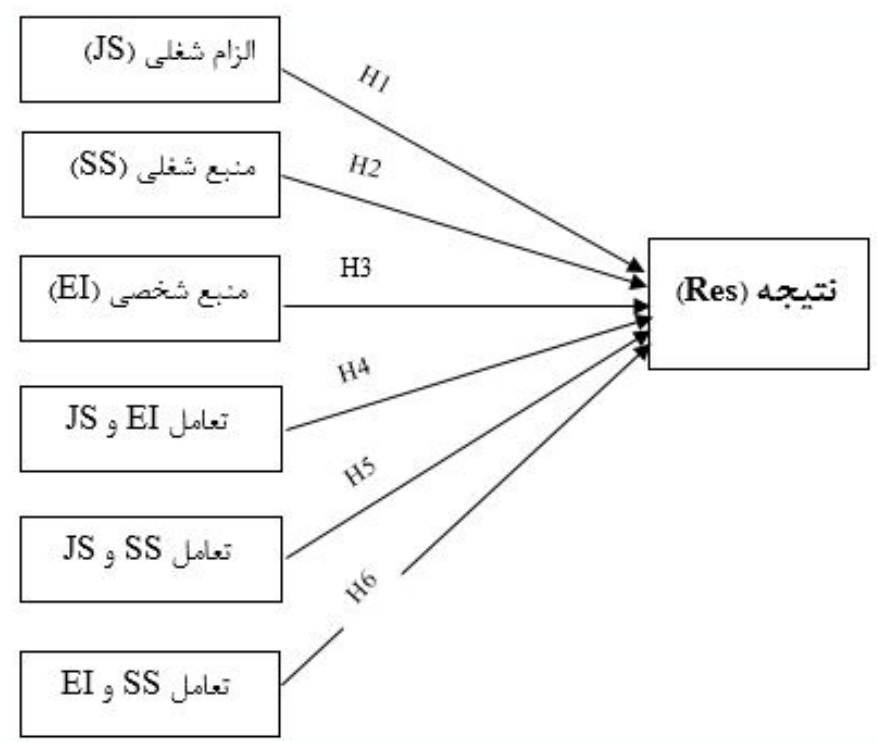

شكل ا. مدل مفهومى برَّرفته از فرضيات مطالعه. H: فرضيه؛ Res: تاب آورى؛ IS: استرس شغلى؛ SS: حمايت اجتماعى؛ EI هوش عاطفى

\section{روش كار}

تحصيلات و سابقه كارى) شامل جهار سازهٔ مكنون با مجموع

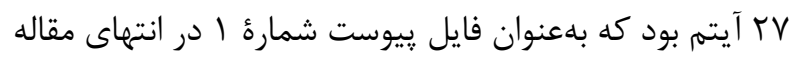
آمده است. از مقياس تابآورى كانر-ديويدسون (CD-RISC)

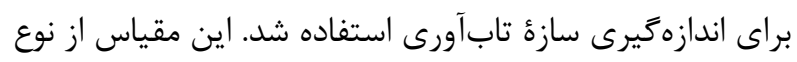

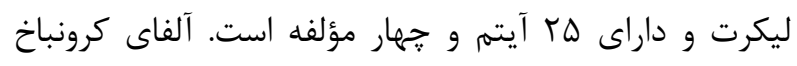

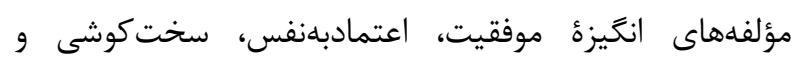

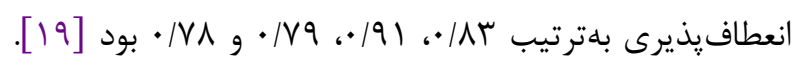

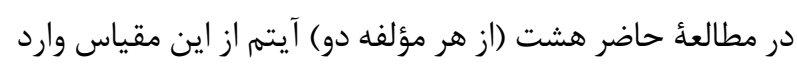

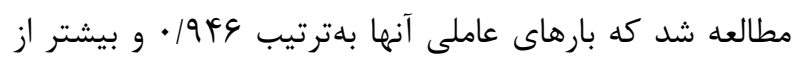
هF همسانى درونى و روايى همكراى سازه هستند.

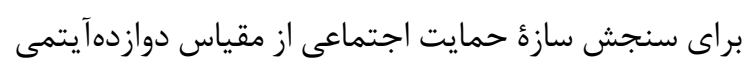

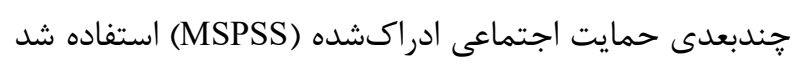

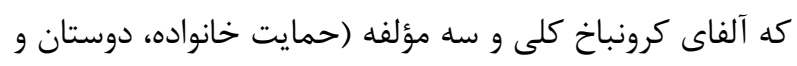

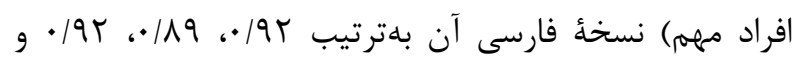

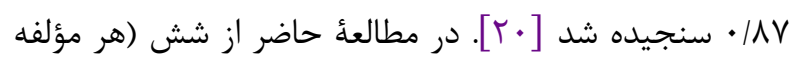

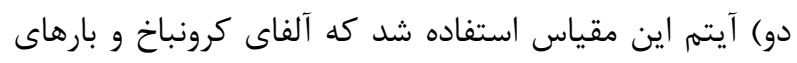

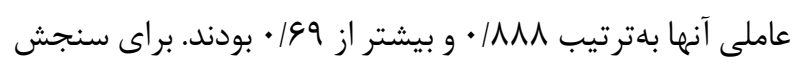

مطالعه، بايش مقطعى و از نوع خوداظهارى است كه جامعأ

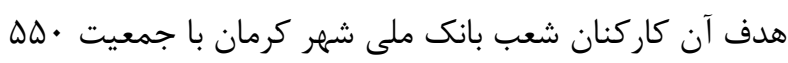

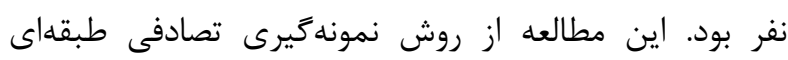

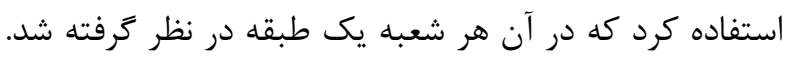
سعى شد از ملاك Tabachnick و Fidell براى انتخاب حدر حداقل

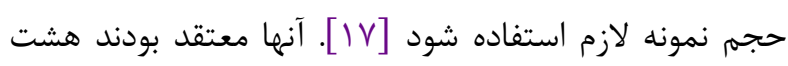
مشاركت كننده به ازاى هر متغير مشاهدهيذير (آيتم) به همراه

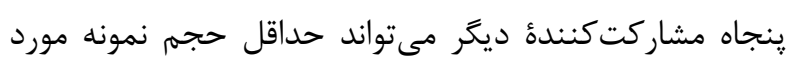

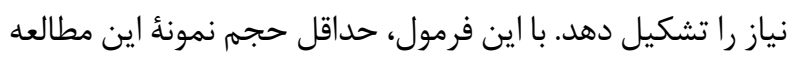

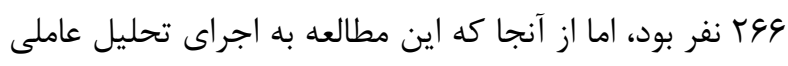

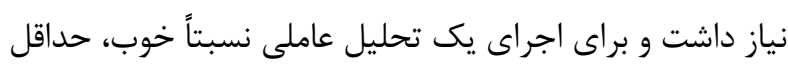

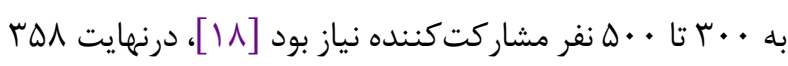

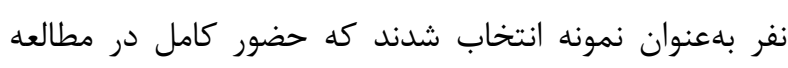

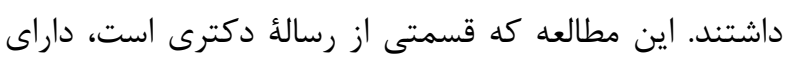

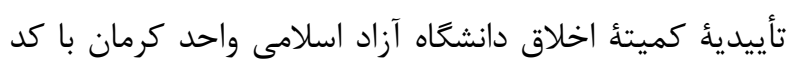
IR.IAU.KERMAN.REC.1399.008 در اين مطالعه از يك يرسشنامه استفاده شد كه علاوه بر مشخصات دموكرافيك (جنسيت، سن، وضعيت تأهل، سطح 
آمارى استفاده شد. درنهايت شاخصهاى كمينهُ تفاوت (CMIN/DF)

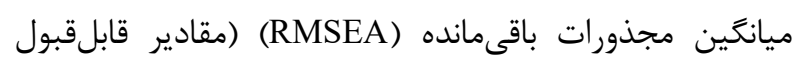

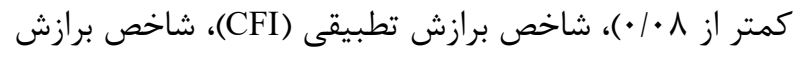

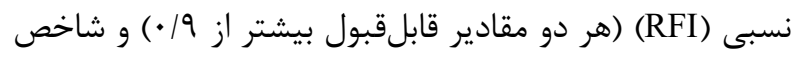

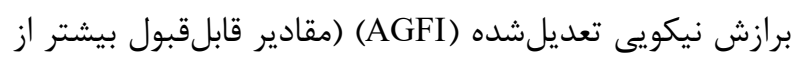
ه/ •) براى بررسى برازش مدل اندازهكيرى و ساختارى مطالعه

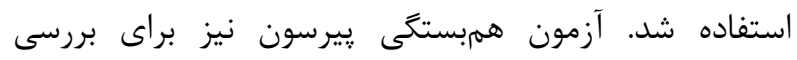
همبستخى جهار سازءٔ مطالعه به كار رفت. از آلفاى كرونباخ و پايايى مركب (CR) با ملاك مارك حداقل مقدار

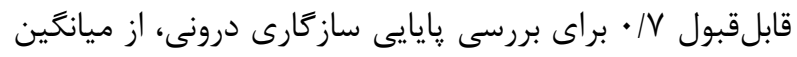

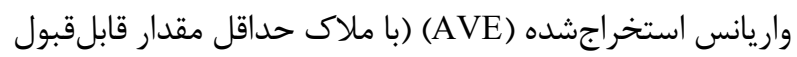

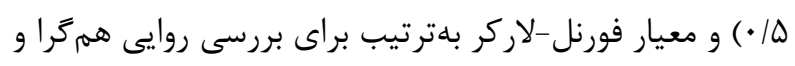
روايى افتراقى سازهاى مورد مطالعه استفاده شد. در مطالعه

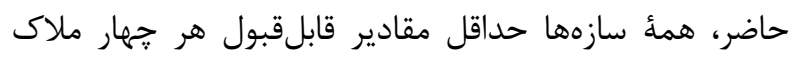

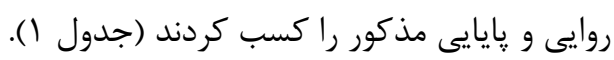

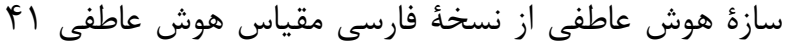

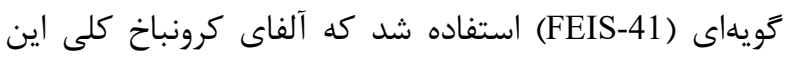

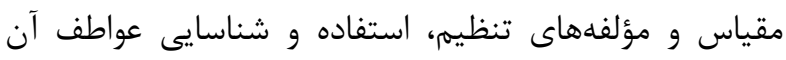

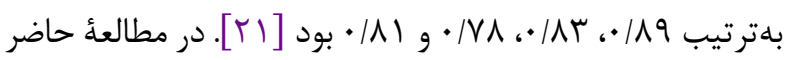

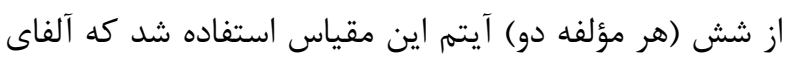

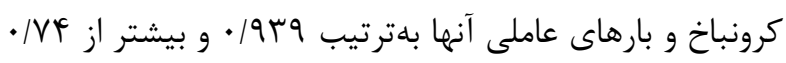

$$
\text { بودند. }
$$

براى سنجش استرس شغلى از يرسشنامة ليكرت استرس

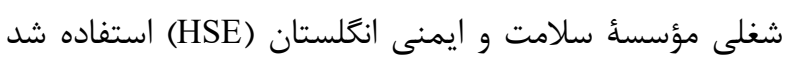

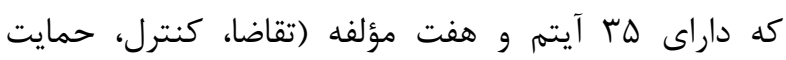
مسئولان، حمايت همكاران، ارتباط، نقش و تغييرات) بود و براى

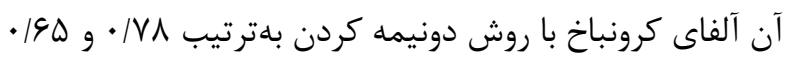

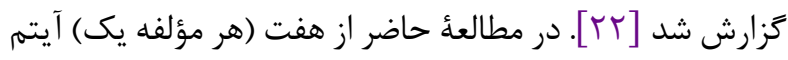

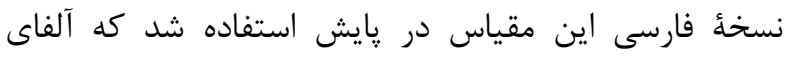

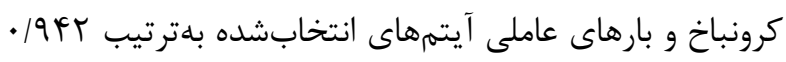

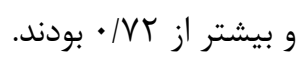

در اين مطالعه از نرمافزارهاى AMOS نسخئ آ و و نسخهُ با براى تحليل (SPSS Inc., Chicago, Ill., USA)

جدول 1. ميانكَين، انحراف معيار، ملاكهاى روايى و پايايیى و همبستكى متغيرهاى مطالعه

\begin{tabular}{|c|c|c|c|c|c|c|c|c|c|}
\hline & $\mathbf{M}$ & SD & $\alpha$ & CR & AVE & SS & EI & JS & Res \\
\hline SS & $\Gamma / \Delta \Delta q$ & $1 / 4 \& Y$ & $\cdot \mid \mathrm{AM} \Lambda$ & $\cdot / 9 \cdot \Delta$ & . 19TV & $(\bullet / \vee 9 \wedge)$ & & & \\
\hline EI & $1 / \mathrm{V} \wedge$. & ./VG. & . /9r9 & .1941 & $\cdot / V r$. & •/У৭६*** & $(\cdot \mid \Lambda \Delta Y)$ & & \\
\hline JS & ه/M & .1995 & .1945 &.$/ 9 F F$ & $\cdot|V| 1$ & $-\cdot \mid \Delta \wedge \Delta * *$ & $-/ \Gamma 9 \Delta * * *$ & $\left(\cdot \mid \wedge F^{\prime}\right)$ & \\
\hline Res & $r / V \cdot r$ & $1 / T Y q$ & .1948 & .1949 & $\cdot / V \cdot r$ & - IVTr**** & $\cdot / V \cdot r$ 兼米 &.$- \mid 9 V Y * * *$ & $(\cdot / A r V)$ \\
\hline
\end{tabular}

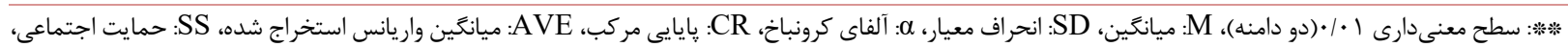

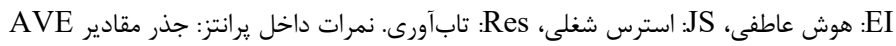

آيتمى طراحى شد. تحليل عاملى اكتشافى به شيوه عامليابى

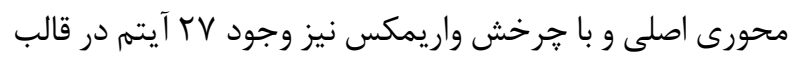

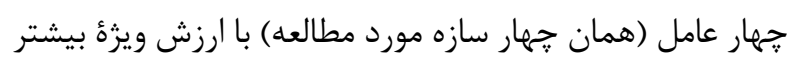

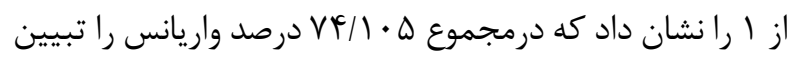

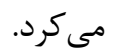

\section{يافته ها}

در مطالعهُ حاضر آله

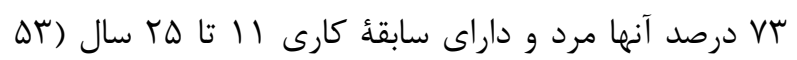

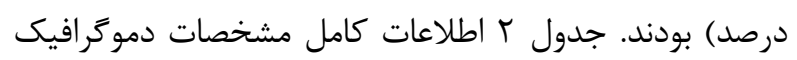

$$
\text { مشار كت كنند كان را ارائه مى بدهد. }
$$

يك مطالعهُ پإيش مقطعى كه در يك زمان خاص از

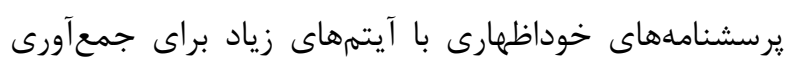

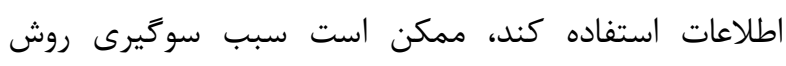

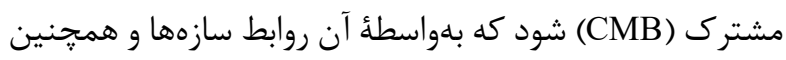

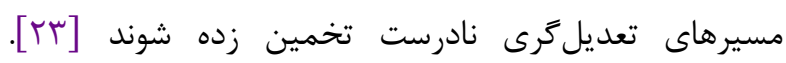

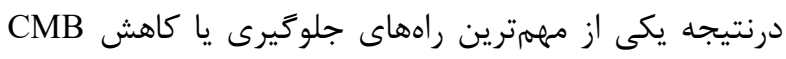

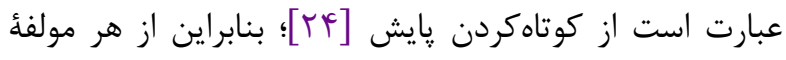

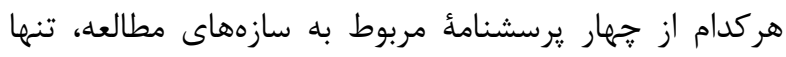

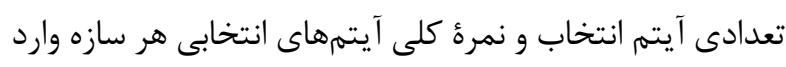

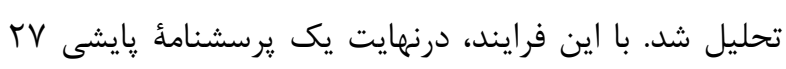


جدول 1 نيز نشان مىدهد كه جهار سازه مورد مطالعه

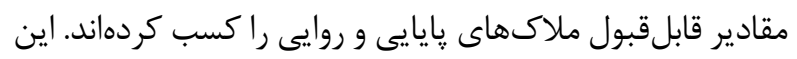

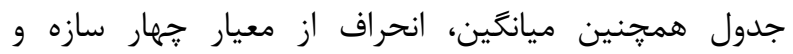

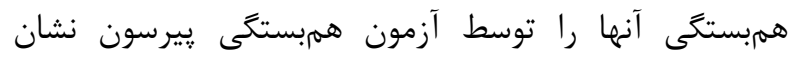

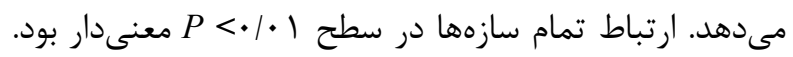

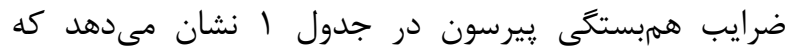

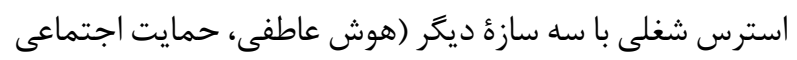

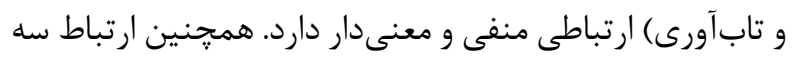

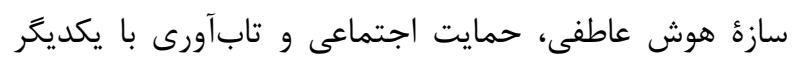
مثبت و معنى دار بودند. مدل اندازمخيرى بلهوسيلة تحليل عاملى تأييدى با جهار

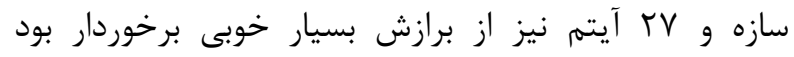

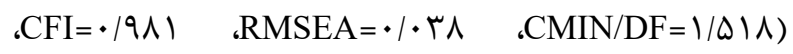

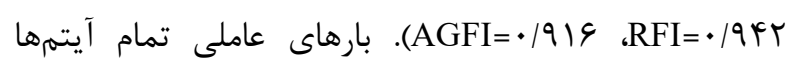
معنى دار و بيشتر از و | • بودند. مدل ساختارى مفروض (شكل

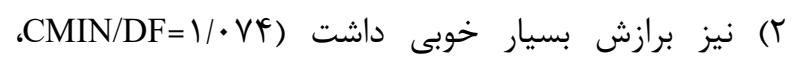
.RFI $=\cdot 19 \wedge \mathrm{V} \quad$ ،CFI $=1 / \cdots \quad$ (RMSEA $=\cdot / \cdot 1 \uparrow$ (AGFI $=\cdot / 9 \vee 9$

شكل r، مدل ساختارى نهايى و ضرايب ركرسيونى

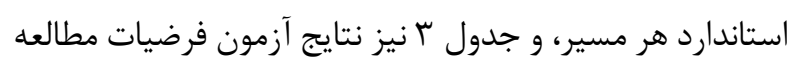

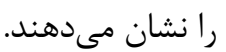

جدول r. مشخصات دموكر افيك مشاركت كنندكًان

\begin{tabular}{|c|c|}
\hline متغير & (درصد) فراوانى \\
\hline \multicolumn{2}{|l|}{ جنسيت } \\
\hline مذكر & TEY $(\%$ \% $)$ \\
\hline 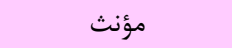 & १९ (\% \%V) \\
\hline \multicolumn{2}{|l|}{ سن (سال) } \\
\hline$r \Delta-r \Delta$ & $\operatorname{IrT}(\%$ HF $)$ \\
\hline rG-Fa & $\operatorname{IVr}(\% \& \Lambda)$ \\
\hline$>F d$ & st $(\% 11)$ \\
\hline \multicolumn{2}{|l|}{ وضعيت تأهل } \\
\hline مجرد & $\Delta /(\% / F)$ \\
\hline متأهل & $r \cdot r(\% \wedge F)$ \\
\hline مطلقه & $\Delta(\% / r)$ \\
\hline \multicolumn{2}{|l|}{ ميزان تحصيلات } \\
\hline دييلهم & q. ( $/ . I V)$ \\
\hline ل ل ل ل ل & Trq $(\% .9 T)$ \\
\hline فوق ليسانس و بالاتر & $\operatorname{Vr}\left(\% r_{\bullet}\right)$ \\
\hline \multicolumn{2}{|l|}{ تجربه كارى (سال) } \\
\hline $1-1$ & 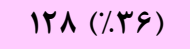 \\
\hline $11-r \cdot$ & $19 \cdot(\% \Delta r)$ \\
\hline$>r_{1}$ & $F \cdot(\% 11)$ \\
\hline
\end{tabular}

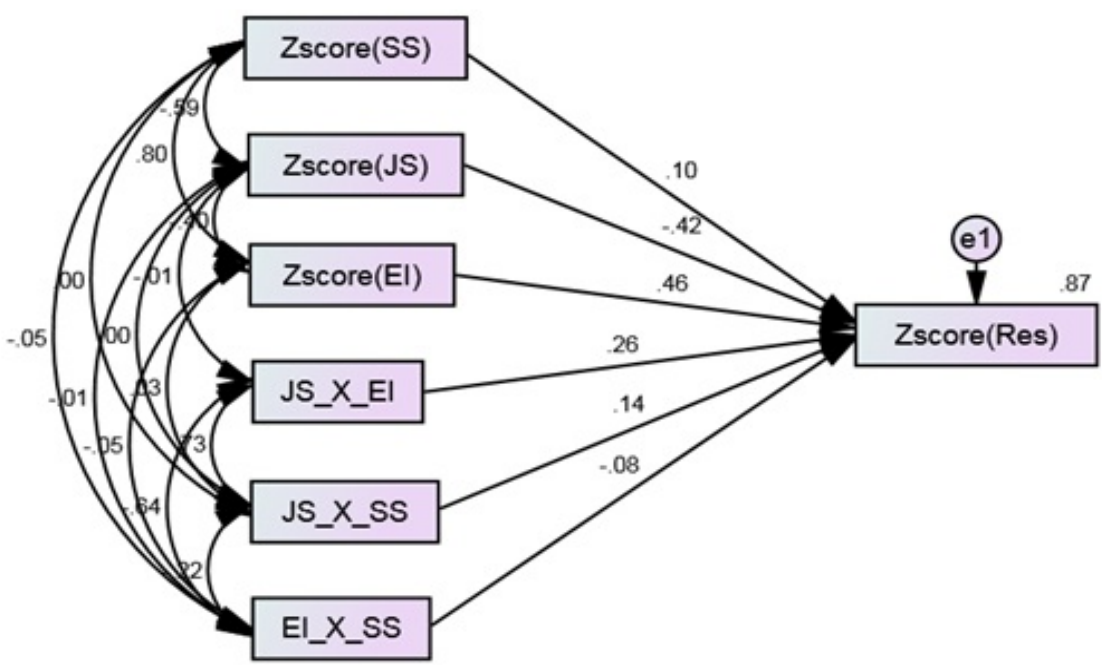

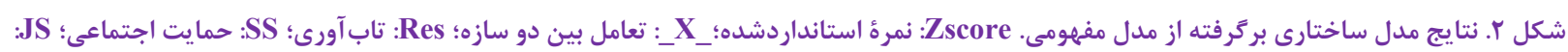
استرس شغلى؛ EI: (E) هوش عاطفى 


\begin{tabular}{|c|c|c|c|c|c|c|}
\hline \multicolumn{3}{|c|}{ رابطه } & ضريب رَرسيونى استاندارد & يى-مقدار & فرضيه & نتيجه \\
\hline ZRes & $<---$ & ZJS & $-\cdot / F T$ & $* * *$ & اول اول & تأييد \\
\hline ZRes & $<---$ & ZSS & $\cdot / 1$ & .1 .94 & 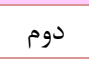 & تأييد \\
\hline ZRes & $<---$ & ZEI & $\cdot / 44$ & $* * *$ & 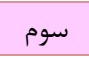 & تأييد \\
\hline ZRes & $<---$ & JS_X_EI & 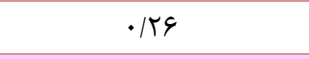 & $* * *$ & جهارم & تأييد \\
\hline ZRes & $<---$ & JS_X_SS &.$/ 14$ & $* * *$ & لينجم & تأييد \\
\hline ZRes & $<---$ & EI_X_SS &.$- \cdot 1 \cdot 1$ & . & 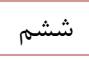 & تأييد \\
\hline
\end{tabular}

تابآورى كاركنان بانكها داشته است [YV]

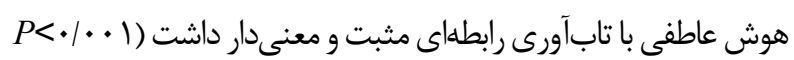

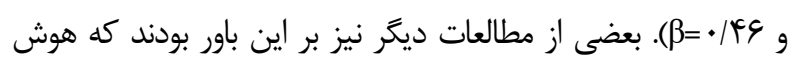

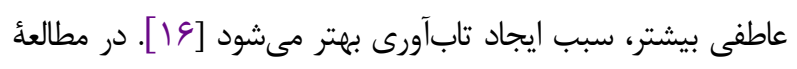

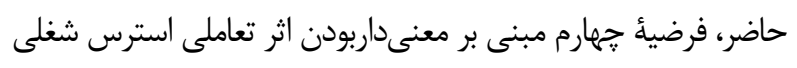

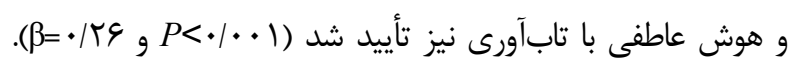

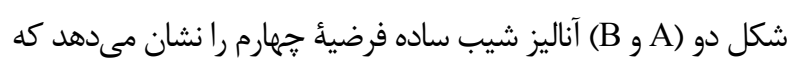
بهترتيب استرس شغلى و هوش عاطفى نقش تعديل

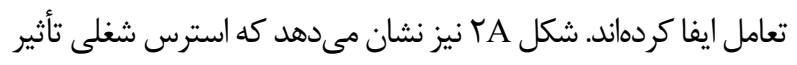

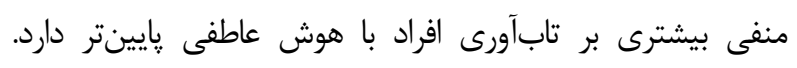
همجنين نشان مىدهد افزايش استرس شغلى سبب افزايش ارتباط إنى

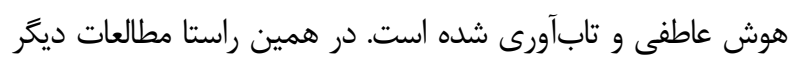

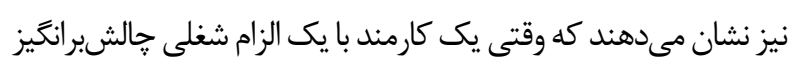

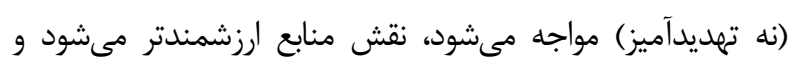

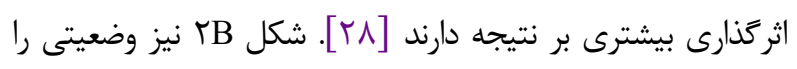
نشان مىدهد كه هوش عاطفى نقش تعديل

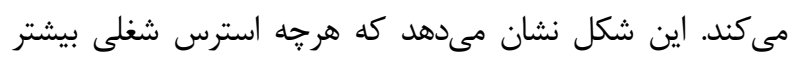

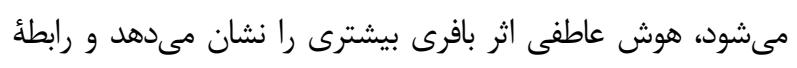

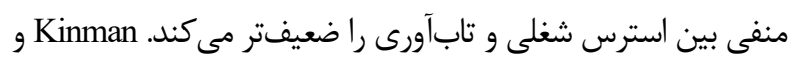

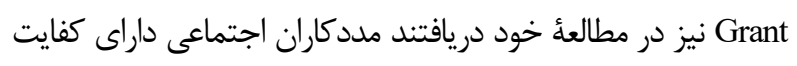

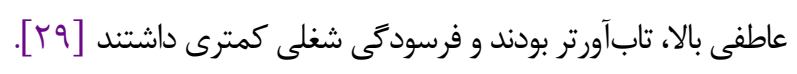

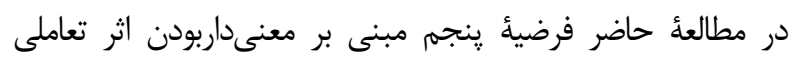

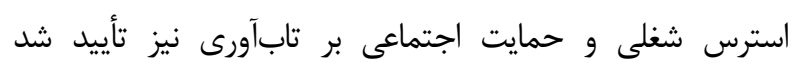

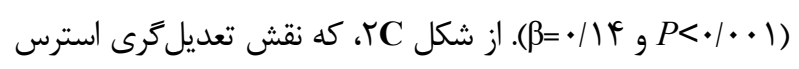
شغلى را در اين تعامل نشان مىدهد، مىتوان دريافت سطح كم

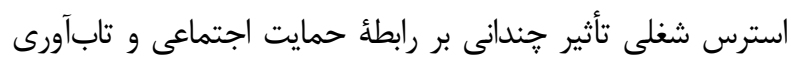

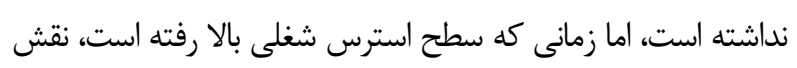

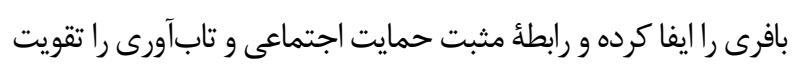

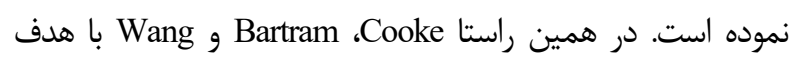
بررسى تأثير حمايت اجتماعى بر تاب آورى فردى هـ • ب نفر از كاركنان
فرضيات مدل مفروض با بررسى يى-مقدار و ضرايب

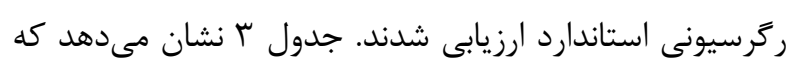

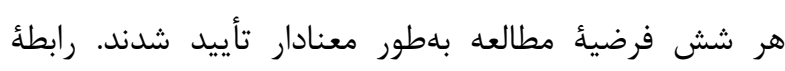

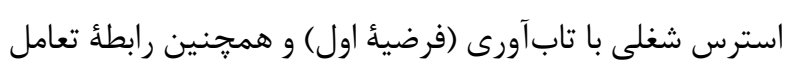

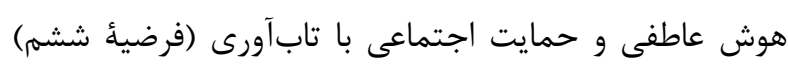

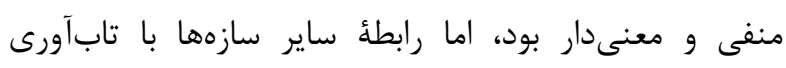

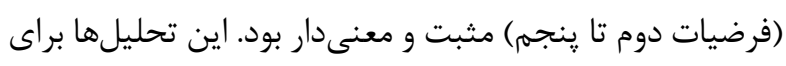

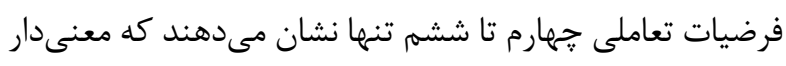

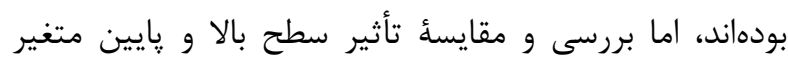

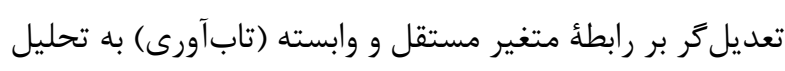
شيب ساده (Simple Slope Analysis) نياز دارد؛ درنتيجه

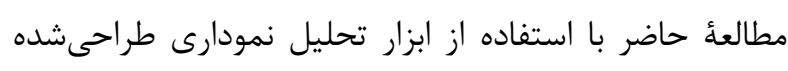

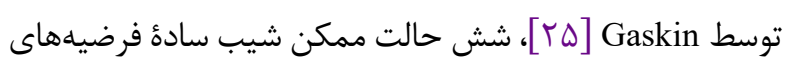

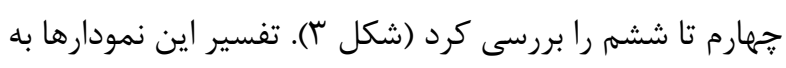
تفضيل در قسمت بعد (قسمت بحث) آمده است.

\section{بحث}

مطالعه حاضر با هدف بررسى رابطؤ استرس شغلى (الزام شغلى)،

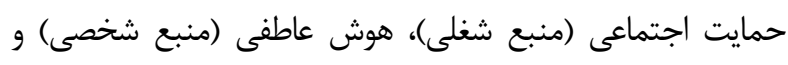

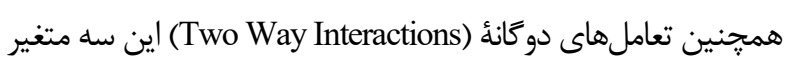
با تابآورى (نتيجه) در قالب مدل JD-R انجام شد. رابطؤ استرس (نسا

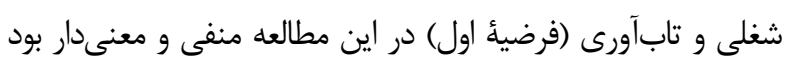

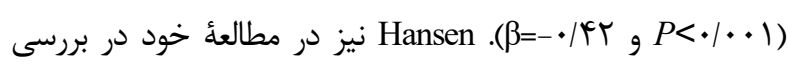
ارتباط استرس شغلى و تابآورى و سلامت مديران به اين نتيجه رسيد

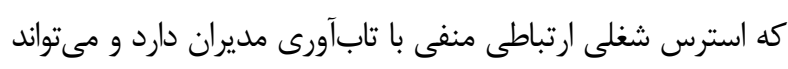

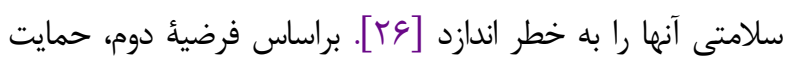

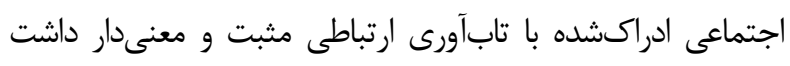

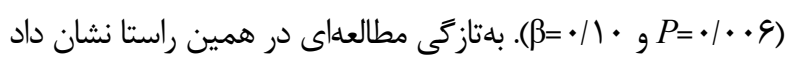

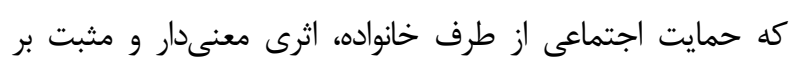


A

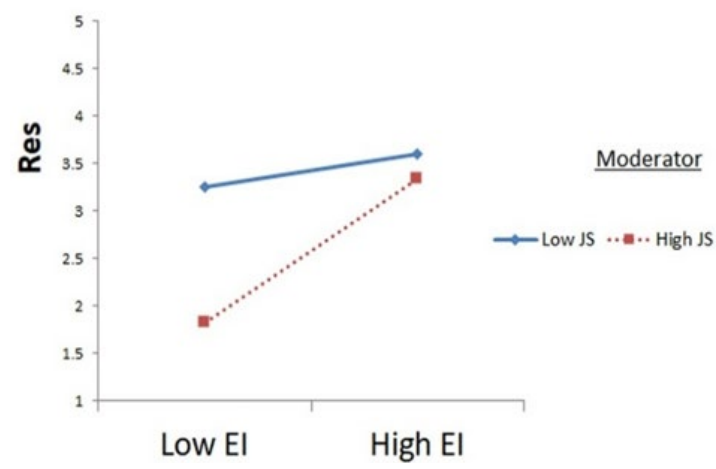

C

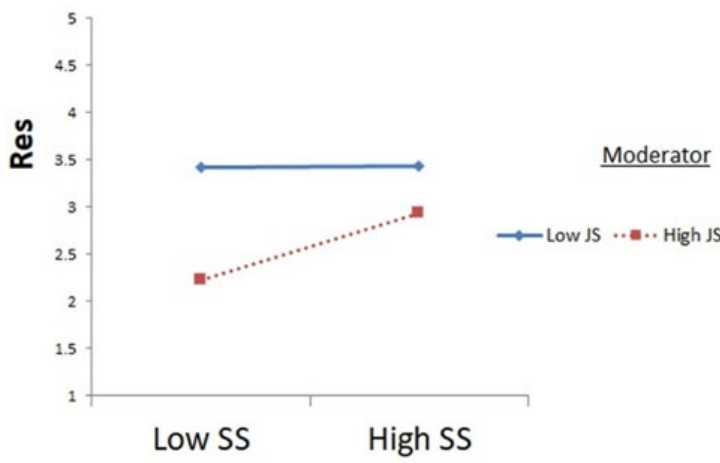

$\mathbf{E}$

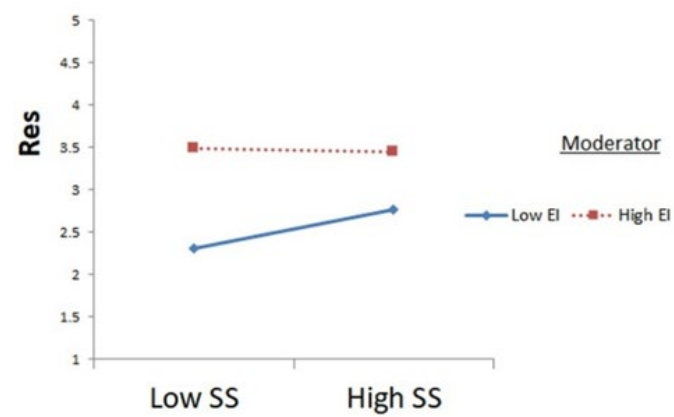

B
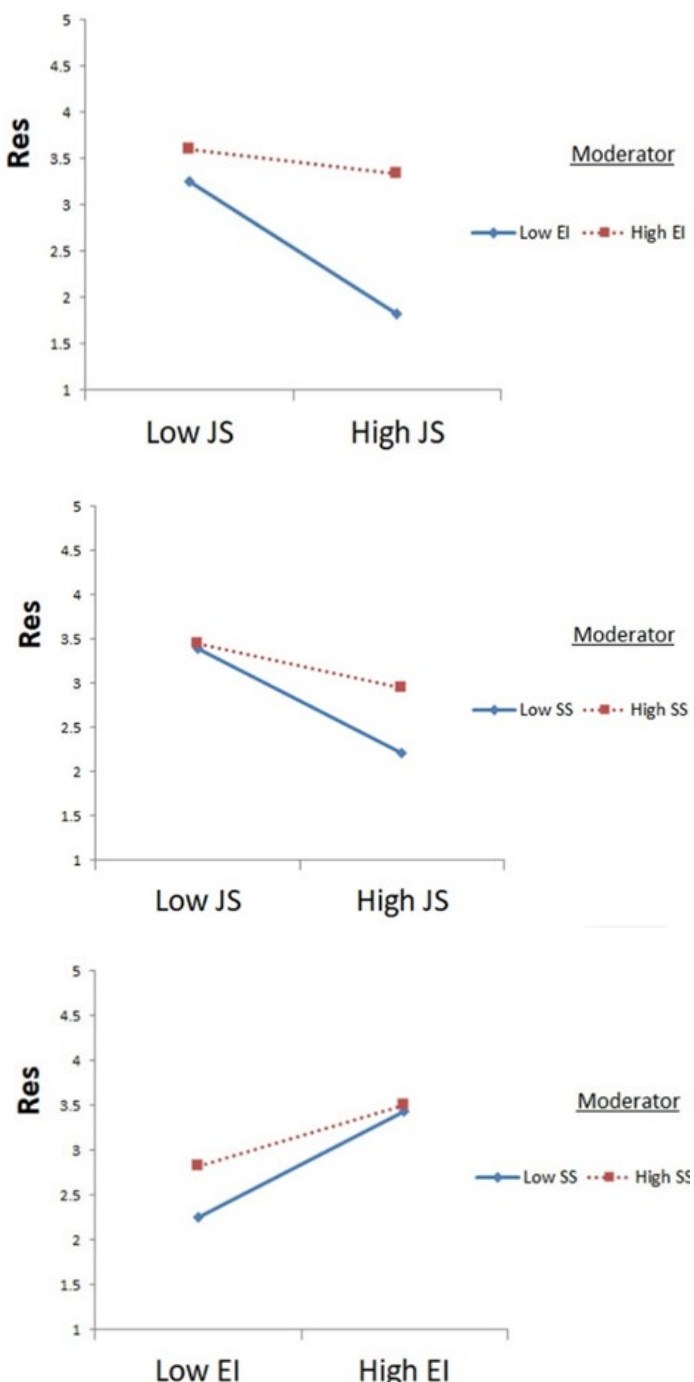

Low El High El

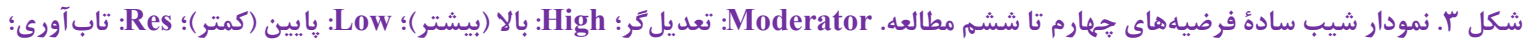

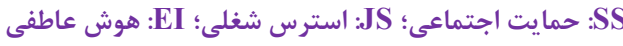

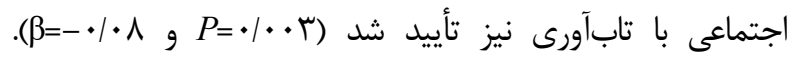

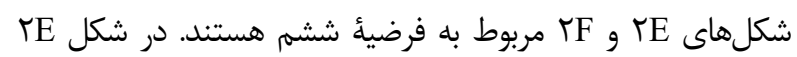
هوش عاطفى نقش تعديل

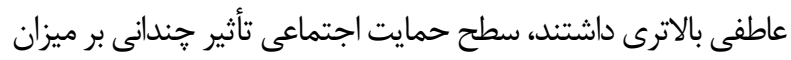

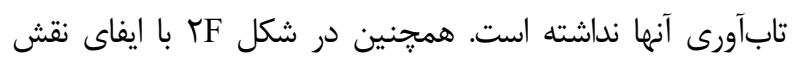

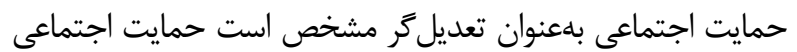
تنها براى افراد با هوش عاطفى بايين نقش بافرى داشته و رابطة مثبت

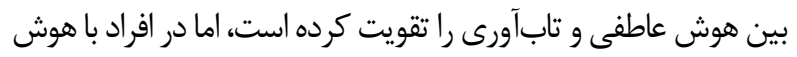
عاطفى بالا، اين نقش بافرى حمايت اجتماعى، بسيار كمرنغ و قابل קشميوشى بوده است؛ بنابراين احتمالاً منبع شخصى هوش عاطفى در مقايسه با منبع شغلى حمايت اجتماعى از اهميت بيشترى برائ إنائ

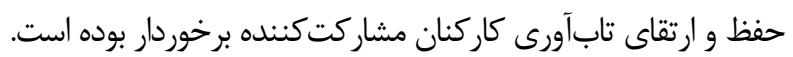

بانكها به اين نتيجه رسيدند كه اين دو رابطهاى مثبت و معنىدار با هم دارند و فشار كارى زياد اين رابطؤ مثبت را تعديل و تقويت مي كى كند

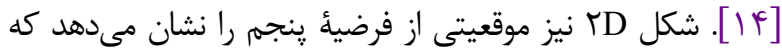

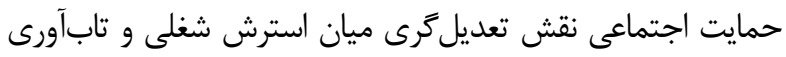
داشته است. اين شكل نشان مىدهد در موقعيتهاى كماسترس، حمايت اجتماعى نقش هندانى بر افزايش تابآورى نداشته، اما در دردي موقعيتهاى يراسترس، نقش بافرى ايفا كرده و رابطة منفى استرس شغلى و تابآورى را تضعيف كرده است. در همين راستا، يك مطالعه

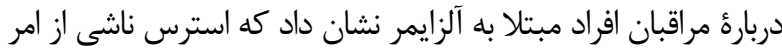
مراقبت، اثر منفى بر تابآورى آنها داشته و حمايت اجتماعى اين رابطؤ

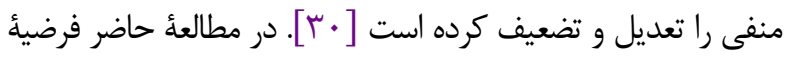
ششم مبنى بر معنى اربودن اثر تعاملى هوش عاطفى و حمايت 


$$
\begin{aligned}
& \text { تقدير و تشكر } \\
& \text { نويسندكان از همأ كسانى كه آنها را در انجام اين يزوهش } \\
& \text { يارى كردهاند، كمال تشكر و قدردانى را دارند. } \\
& \text { تأييدية اخلاقى }
\end{aligned}
$$

$$
\text { تعارض منافع }
$$

بين نويسندًان اين مقاله هيجَّونه تعارضى در منافع وجود

$$
\text { سهمم نويسندكان }
$$

مفهومسازى: فرشته محسنى تكلو، سنجر سلاجقه، محمدتقى

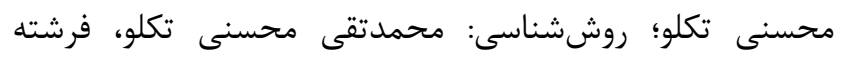

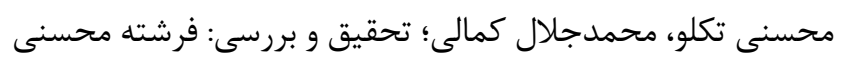

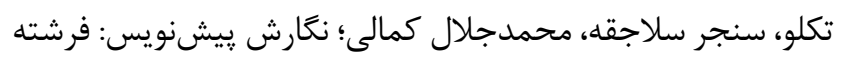
محسنى تكلو، سنجر سلاجقه، محمدتقى محسنى تكلو، ويراستارى

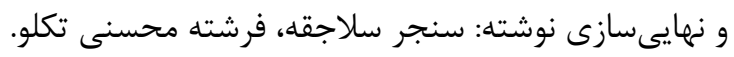

$$
\text { منابع مالى منابع مالى اين مطالعه توسط نويسندكان تأمين شده است. }
$$

\section{References}

1. Giorgi G, Arcangeli G, Perminiene M, Lorini C, ArizaMontes A, Fiz-Perez J, Di Fabio A, Mucci N. Workrelated stress in the banking sector: a review of incidence, correlated factors, and major consequences. Frontiers in psychology. 2017;8:2166.

[DOI:10.3389/fpsyg.2017.02166] [PMID] [PMCID]

2. Wang J, Cooke FL, Huang W. How resilient is the (future) workforce in C hina? A study of the banking sector and implications for human resource development. Asia Pacific J. Hum. Resour. 2014;52(2):132-54. [DOI:10.1111/1744-7941.12026]

3. Avey JB, Luthans F, Jensen SM. Psychological capital: A positive resource for combating employee stress and turnover. Hum Resour Manage. 2009 Sep;48(5):677-93. [DOI:10.1002/hrm.20294]

4. Kalisch R, Baker DG, Basten U, Boks MP, Bonanno GA, Brummelman E, Chmitorz A, Fernàndez G, Fiebach CJ, Galatzer-Levy I, Geuze E. The resilience framework as a strategy to combat stress-related disorders. Nat. Hum.
مديران منابع انسانى مى تواند از نتايج اين مطالعه در انتخاب و استخدام

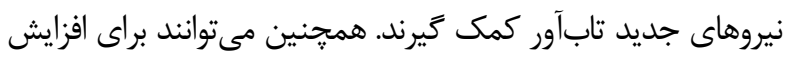

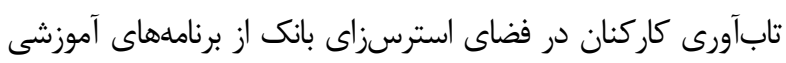

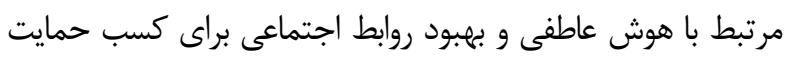

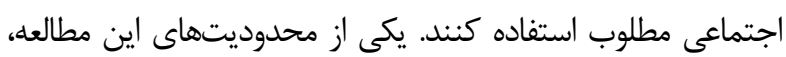

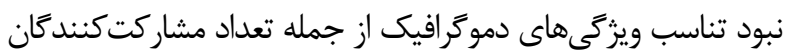
براساس جنسيت و وضعيت تأهل بود. محدوديت ديكر اينكه نمى نوان

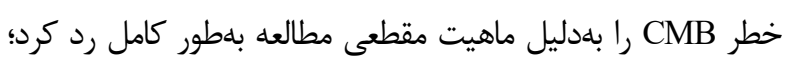

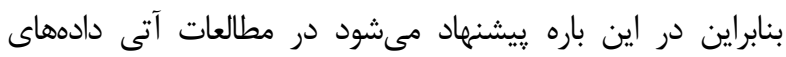
متغيرهاى مستقل و وابسته در دو مرحله و بازء زمانى متفاوت داني جمعآورى شوند و از رويكردى طولى براى مطالعه استفاده شود.

$$
\text { نتيجه كيرى }
$$

نتايج اين مطالعه نشان مى دهد كه منابع و الزاماتى مانند هوش

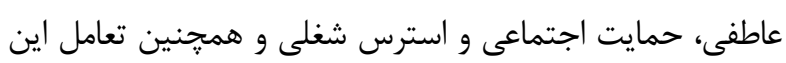

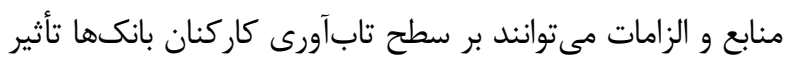

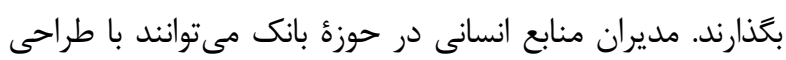

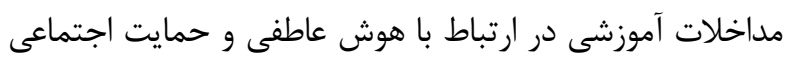

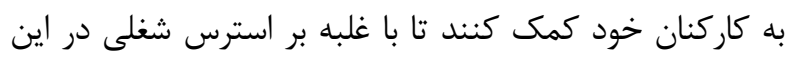

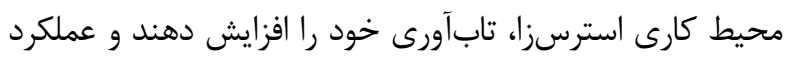

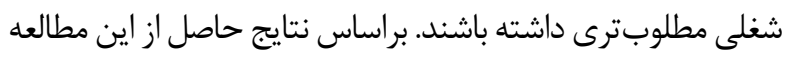

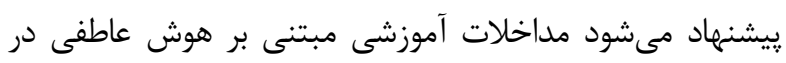
مقايسه با حمايت اجتماعى در اولويت قرار بكيرد.

Behav. 2017;1(11):784-90. [DOI:10.1038/s41562-0170200-8] [PMID]

5. Jackson D, Firtko A, Edenborough M. Personal resilience as a strategy for surviving and thriving in the face of workplace adversity: A literature review. J Adv Nurs. 2007;60(1):1-9. 2648.2007.04412.x] [PMID]

6. Chmitorz A, Kunzler A, Helmreich I, Tüscher O, Kalisch $\mathrm{R}$, Kubiak T, Wessa M, Lieb K. Intervention studies to foster resilience-A systematic review and proposal for a resilience framework in future intervention studies. Clin Psychol Rev. 2018 1;59:78-100. [DOI:10.1016/j.cpr.2017.11.002] [PMID]

7. Bakker AB, Demerouti E. Job demands-resources theory. Wellbeing: A complete reference guide. 2014;1-28. [DOI:10.1002/9781118539415.wbwell019]

8. Schaufeli WB, Taris TW. A critical review of the job demands-resources model: Implications for improving work and health. Bridging occupational, organizational 
and public health. 2014;43-68. [DOI:10.1007/978-94$\underline{007-5640-3 \quad 4]}$

9. Demerouti E, Bakker AB, Nachreiner F, Schaufeli WB. The job demands-resources model of burnout. J Appl Psychol. 2001;86(3):499. [DOI:10.1037/00219010.86.3.499] [PMID]

10. Lazarus RS, Folkman S. Stress, appraisal, and coping. Springer publishing company; 1984 Mar 15.

11. Cohen S, Wills TA. Stress, social support, and the buffering hypothesis. Psychol Bull. 1985;98(2):310. [DOI: 10.1037/0033-2909.98.2.310] [PMID]

12. Zimet GD, Dahlem NW, Zimet SG, Farley GK. The multidimensional scale of perceived social support. J Pers Assess. 1988;52(1):30-41. [DOI:10.1207/s15327752jpa5201 2]

13. Bardoel EA, Pettit TM, De Cieri H, McMillan L. Employee resilience: an emerging challenge for HRM. Asia Pacific J. Hum. Resour. 2014 Jul;52(3):279-97. [DOI:10.1111/1744-7941.12033]

14. Cooke FL, Wang J, Bartram T. Can a supportive workplace impact employee resilience in a high pressure performance environment? An investigation of the Chinese banking industry. J Appl Psychol. 2019;68(4): 695-718. [DOI:10.1111/apps. 12184]

15. Salovey P, Mayer JD. Emotional intelligence. Imagin Cogn Pers. 1990;9(3):185-211. [DOI:10.2190/DUGGP24E-52WK-6CDG]

16. Schneider TR, Lyons JB, Khazon S. Emotional intelligence and resilience. Pers. Individ. Differ. 2013;55(8):909-14. [DOI:10.1016/i.paid.2013.07.460]

17. Tabachnick BG, Fidell LS, Ullman JB. Using multivariate statistics. Boston, MA: Pearson; 2007 Mar 3.

18. Comrey AL, Lee HB. A first course in factor analysis. Psychology press; 2013 Nov 12. [DOI:10.4324/9781315827506]

19. Khoshouei MS. Psychometric evaluation of the ConnorDavidson resilience scale (CD-RISC) using Iranian students. Int. J. Test. 2009;9(1):60-6. [DOI:10.1080/15305050902733471]
20. Bagherian-Sararoudi R, Hajian A, Ehsan HB, Sarafraz MR, Zimet GD. Psychometric properties of the Persian version of the multidimensional scale of perceived social support in Iran. Int. J. Prev. Med. 2013;4(11):1277.

21. Besharat MA. Psychometric properties of Farsi version of the Emotional Intelligence Scale-41 (FEIS-41). Pers. Individ. Differ. 2007;43(5):991-1000. [DOI:10.1016/i.paid.2007.02.020]

22. Azad ME, Gholami FM. Reliability and validity assessment for the HSE job stress questionnaire. 2011.

23. Rodríguez-Ardura I, Meseguer-Artola A. How to prevent, detect and control common method variance in electronic commerce research. J. Theor. Appl. Electron. Commer. Res. 2020;15(2):i-v. [DOI:10.4067/S071818762020000200101]

24. MacKenzie SB, Podsakoff PM. Common method bias in marketing: Causes, mechanisms, and procedural remedies. J. Retail. 2012;88(4):542-55. [DOI:10.1016/j.jretai.2012.08.001]

25. Gaskin J. Way Interactions. Stats Tools Package Available online at: http://statwiki kolobkreations com.

26. Hansen E. The Effects of Mindfulness on Work-Related Stress, Wellbeing, Recovery Quality, and Employee Resilience. 2016.

27. Bose S, Pal D. Impact of Employee Demography, Family Responsibility and Perceived Family Support on Workplace Resilience. Glob. Bus. Rev. 2020;21(5):124962. [DOI:10.1177/0972150919857016]

28. Hakanen JJ, Bakker AB, Demerouti E. How dentists cope with their job demands and stay engaged: The moderating role of job resources. Eur. J. Oral Sci. 2005;113(6):47987. [DOI:10.1111/j.1600-0722.2005.00250.x] [PMID]

29. Kinman G, Grant L. Exploring stress resilience in trainee social workers: The role of emotional and social competencies. Br. J. Soc. Work. 2010;41(2):261-75. [DOI:10.1093/bjsw/bcq088]

30. Wilks SE, Croom B. Perceived stress and resilience in Alzheimer's disease caregivers: Testing moderation and mediation models of social support. Aging Ment Health. 2008;12(3):357-65. [DOI:10.1080/13607860801933323] [PMID] 


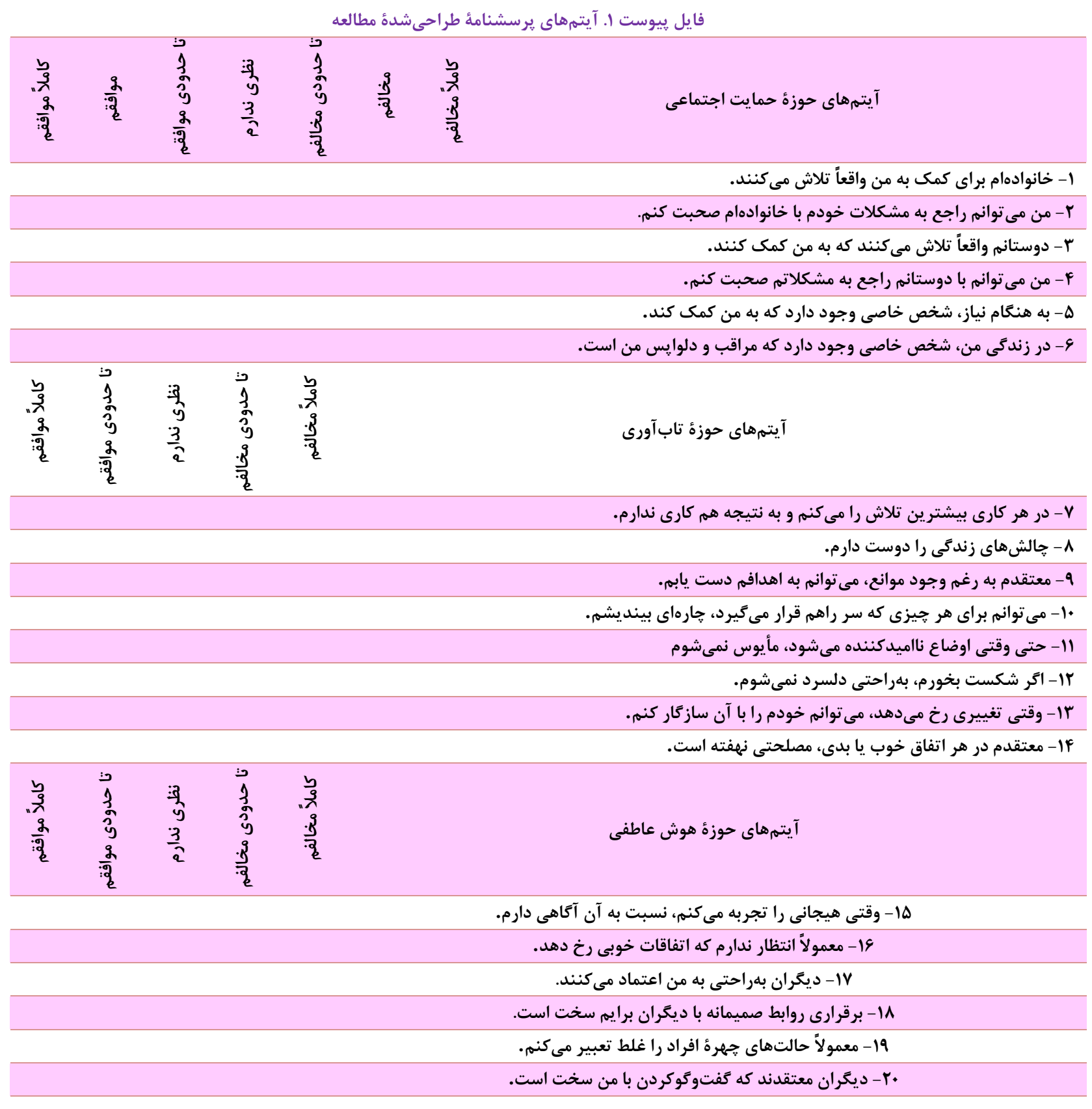

$$
\text { آ آيتمهاى حوزة استرس شغلى }
$$

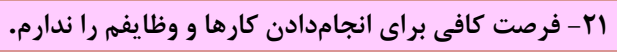

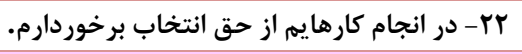

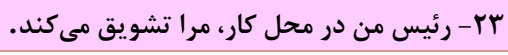

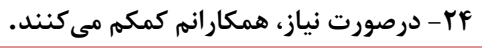

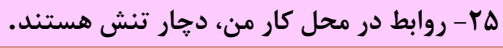

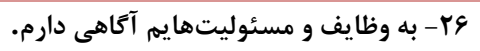

rV وقتى تغييراتى در كارها به وجود مى آيد، بدروشنى به عملى بودن آنها آكاهمم. 